\title{
THE EFFECT OF HAEMODIALYSIS IN MYASTHENIA GRAVIS
}

\author{
BY \\ ERNST STRICKER, HEINRICH THÖLEN, MARIE-AGNES MASSINI, \\ and HANS STAUB
}

\author{
From the Medizinische Universitätsklinik, Basel, Switzerland
}

As long ago as the year 1900 Campbell and Bramwell suspected the presence of a circulating toxic factor in myasthenia gravis. The first effective therapy was reported in 1934, when Walker described the benefits of prostigmine, a potent anticholinesterase. The apparent similarity in the response of myasthenic symptoms to neostigmine and the antagonism of curare poisoning by the same drug were noted at once. The presence of some "curare-like" compound has therefore been suggested and has found support in the work of Walker (1938) and Wilson and Stoner (1944). Struppler (1955) and recently Tsukiyama, Nakai, Mine, and Kitani (1959), and Nastuk, Strauss, and Osserman (1959) considered their results to be inconclusive.

In favour of the hypothesis of a circulating neuromuscular blocking agent are the following observations. A cuff is placed on a limb and inflated above venous pressure, and the limb subsequently exercised to exhaustion. Sometimes the ocular symptoms of myasthenia are aggravated when the tourniquet is suddenly released. Wilson and Stoner obtained venous blood from myasthenics under such conditions and found that the serum produced a depression in the twitch height of frog sartorius muscle. Struppler reported a similar action of serum from myasthenics injected into dogs. Tsukiyama et al. found electromyographic evidence of what they call a myasthenic substance in man and rabbit. Schwarz (1952) induced fatigue in normal man when the serum of myasthenics was injected intramuscularly. However, he saw no change in the normal subjects after large blood transfusions from myasthenics and no beneficial effect of exchange transfusion in a myasthenic patient. Reports of transient neonatal myasthenia in children born of myasthenic mothers have repeatedly been published.

On the assumption that some neuromuscular blocking chemical is present, we thought it worth while to attempt to remove such a substance by haemodialysis.
Methods

Medication was maintained at the usual dose until the start of the dialysis in the morning. For haemodialysis, the instrument developed by Alvall was used. A cellulose tube manufactured by the Visking Corporation, Chicago, was used. It has a total surface area of $1.4 \mathrm{~m}^{2}$. Blood taken from the radial artery was pumped through the tubing and brought back to a vein in the arm or leg. The extracorporeal blood volume was $1,600-1,900 \mathrm{ml}$. An additional 200-1,800 ml. blood (non-myasthenic donors) had to be given because of a fall in blood pressure in the course of the dialysis. Blood flow was $100-200 \mathrm{ml}$. per minute. A continuous dialysis was maintained for 14 hours in seven patients and for eight, 12, and 20 hours on three different occasions in one patient. The bath fluid of 135 litres was renewed six to 12 times during the dialysis. The bath fluid contained $660 \mathrm{mg} . \% \mathrm{NaCl}$, $225 \mathrm{mg} . \% \mathrm{NaHCO}_{3}, 18.5 \mathrm{mg} . \% \mathrm{CaCl}_{2}$, and $200 \mathrm{mg} . \%$ glucose. In all but one case, $10 \mathrm{mg} . \%$ of $\mathrm{MgCl}_{2}$ was added. Potassium content varied from 12 to $20 \mathrm{mg}$. \% ( 22.5 to $38 \mathrm{mg}$. \% of $\mathrm{KCl}$ ).

\section{Results}

Eight patients were dialysed between September, 1959, and January, 1960. One man, aged 46, with only minimal ocular symptoms, in whom the diagnosis of myasthenia gravis is not beyond doubt and who did not require any medication, was unchanged by haemodialysis. In two women, aged 37 and 46, the existing severe myasthenic symptoms were relieved and during the dialysis they required almost no medication. The previous amount of drug had to be resumed very shortly after dialysis. A later control period in one of these two patients showed that she tolerated withdrawal of the drugs for a period of time commensurate with the dialysis. We have classed all three of these patients as " unimproved". Five patients with marked to severe myasthenia were undoubtedly improved. In these seven patients with marked symptoms intravenous "tensilon" produced improvement before as well as after dialysis.

\section{Illustrative Case Reports}

Case 1.-In February, 1956, Mrs. E. D., a housewife, aged 46, developed progressive difficulty with speech and 
swallowing. She entered the hospital in July of that year and myasthenia gravis was diagnosed on the grounds of a right ptosis and impaired speech and deglutition. A malignant thymoma invading the right thoracic wall and lung was found and removed. Post-operative $x$-ray treatment had to be abandoned because of mental disturbances which subsequently disappeared. During the following three years she was reasonably controlled with neostigmine (prostigmine) and later with up to $540 \mathrm{mg}$. pyridostigmine ("mestinon") daily. Several periods of myasthenic deterioration associated with upper respiratory infections required admission to hospital. She was usually able to cook but could to little other housework. In July, 1959, she re-entered hospital with an increase of extraocular muscle weakness and impaired breathing. Increasing the dosage of drugs up to $200 \mathrm{mg}$. " mestinon " intramuscularly daily was unsatisfactory. Dialysis on August 28 for an eight-hour period improved ptosis, speech, and swallowing, and the "mestinon" was reduced to only $40 \mathrm{mg}$. intramuscularly on the day of dialysis and to $120 \mathrm{mg}$. on the following day. The patient felt much relieved and was again able to swallow the tablets. Because of the marked benefit of the dialysis, it was decided to repeat the procedure on September 10, this time for 20 hours. Again the ptosis and swallowing improved. She required no "mestinon" at all during dialysis and for 12 hours afterwards. A general state of improvement was indicated by her requirement of only 120 to $150 \mathrm{mg}$. " mestinon" intramuscularly daily during the next two weeks. After this time, the "mestinon" had to be increased again, but with up to $270 \mathrm{mg}$. she was able to walk in the ward. At the end of the month of October, she had so deteriorated again that constant gastric drip feeding became necessary. On October 27, in a desperate state despite a daily dose of $240 \mathrm{mg}$. " mestinon" intramuscularly, a third dialysis of 12 hours was performed and again the patient improved remarkably. For example, after dialysis, her cough was of sufficient strength to clear her throat and she could drink and breathe freely. Mestinon could again be kept at $80 \mathrm{mg}$. intramuscularly daily during the next three weeks after which time it again had to be increased to $250 \mathrm{mg}$. daily. Further deterioration was not controlled with increased " mestinon". On December 26, tracheotomy had to be performed to clear the airways, and on January 1 , the patient died somewhat unexpectedly after blood gases had been shown to be normal. Necropsy 24 hours after death revealed multiple deposits of thymoma tissue in the right pleural cavity and in widely scattered lymph nodes. There was a bilateral suppurative bronchopneumonia.

Case 2.-Miss C. R., an office clerk aged 35, developed a left ptosis and difficulty with swallowing for three months during the spring of 1955 . A slowly progressive impairment of speech and singing developed during the course of 1957. Swallowing, which had not been quite normal since 1955, became worse. In February, 1958, myasthenia gravis was diagnosed at the Neurologische Poliklinik, Zürich, and treatment was started with prostigmine and up to $600 \mathrm{mg}$. "mestinon" daily. In the summer of 1958 , after $x$-ray treatment to the thymus, there was transitory improvement and it was possible to reduce medication. During the early part of 1959 she was able to work but in the last six months typewriting became progressively difficult and her hands were sometimes so weak in the evenings that she could not pull out an electric plug. Because of diarrhoea and cramps, medication could not be increased over $300 \mathrm{mg}$. "mestinon" daily and $15 \mathrm{mg}$. prostigmine every second morning. Ten days before dialysis, she developed an upper respiratory infection and nearly suffocated. Dialysis on January 12 for 14 hours resulted in marked improvement of facial mobility, articulation, swallowing, and in the strength of her arms. For eight days she took only 60 mg. " mestinon" twice daily, but had to increase it again afterwards. After two weeks she felt much weaker, though she still considered her condition to be better than before dialysis.

Case 3.-In October, 1953, Mr. W. H., a typewriter mechanic, aged 25 , noted that he was unable to comb his hair in the evening. This always followed a day of strenuous military training. He felt fit again the next morning. In January, 1956, his left eyelid drooped and in March of that year swallowing became difficult. In the Neurologische Poliklinik, Basel, a presumptive diagnosis of myasthenia gravis was made and confirmed by the dramatic improvement of his symptoms with 120 mg. " mestinon" daily. In May, 1956, he abruptlyo discontinued taking "mestinon", and was brought toक the hospital as an emergency with respiratory distress severe bronchitis, and partial atelectasis of the lung Prostigmine immediately improved his condition ando he was discharged on a dose of $180 \mathrm{mg}$. "mestinon " daily. Following this he was able to work taking slowlye increasing doses of up to $1,200 \mathrm{mg}$. " mestinon" daily In the mornings he was unable to dress himself withount taking $120 \mathrm{mg}$. "mestinon" an hour before. Dialysis" on October 14 for 14 hours led to marked improvement of his overall strength. The next morning, without any "mestinon" for 24 hours, he was able to get up and comb his hair without any support of the left arm, an action which he was previously unable to do, even under drug action. During the following days he slowly had to increase the dosage of "mestinon" to $600 \mathrm{mg}$. daily, but despite this reduced dosage he felt stronger than before the dialysis. Whereas before dialysis he frequently had to stop his car and take tablets before he could operate the pedals again, during the three weeks after dialysis he was never forced to interrupt his driving in this way. He admits, however, that he started normal work only two weeks after dialysis and his drug requirements are dependent on his mood. After one month he was back to his previous medication schedule.

Case 4.-In 1953, Mrs. E. G., a housewife, aged 27, noticed facial weakness while laughing and difficulty with speech and swallowing. In 1954, she was diagnosed as having myasthenia gravis at the Neurologische Poliklinik, Basel. Her symptoms could be controlled well with $180 \mathrm{mg}$. " mestinon" and, during a pregnancy in 1957, she improved, requiring only $90 \mathrm{mg}$. " mestinon" daily. After delivery in January, 1958, she deteriorated markedly and was not fully compensated with $360 \mathrm{mg}$. " mestinon" 
daily. In March, 1958, it was found that she responded better to prostigmine. To do her household tasks, she required $240-270 \mathrm{mg}$. prostigmine daily. She had to be awakened twice a night by her husband to take prostigmine and occasionally the drug had to be given hypodermically. Because of increased fatigue during the second half of her menstrual cycle, she was treated with large doses of chorionic gonadotropin. This makes her feel unwell, but she believes that it improves her myasthenic symptoms. Dialysis on October 16 for 14 hours led to marked improvement. No drugs were given until the end of dialysis and she felt nearly as well during dialysis as with full prostigmine therapy. She could drink two glasses of beer without hesitation after $1 \mathrm{mg}$. prostigmine intramuscularly, something she was unable to do before. On the following day she was very active and took no drugs at all. After discharge she started with $180 \mathrm{mg}$. " mestinon" daily. This had to be increased to $360 \mathrm{mg}$. during the next three days after which she replaced the "mestinon" again by prostigmine. After two weeks she had reached her previous prostigmine level.

\section{Discussion}

There are several ways of explaining the beneficial effects of dialysis.

First, all the patients may have been suffering from an overdosage of anticholinesterase drugs and the dialysis then removed the offending agent. This is extremely unlikely as all patients had a positive response to "tensilon" both before and after dialysis.

In the second place, the patients may have had an improvement not specifically related to the dialysis as such but rather to some other element in the procedure. It has been often noted that some myasthenics have a "spontaneous" improvement after such procedures as appendectomy or minor surgery. These remissions are not common. In our group, however, five out of eight patients improved which makes it much more likely that the result is a consequence of some specific effect of the dialysis.

Thirdly, the patients may have had a favourable psychological response to this new treatment which made them feel or wish that they had been improved when, in fact they were not better at all. For this reason, it would be most desirable to have an objective measure of the intensity of the myasthenic symptoms. This is notoriously difficult to accomplish. It is possible to show the influence of edrophonium chloride ("tensilon") on muscle power using kymographic tracings of a Mosso ergograph following electrical stimulation of a nerve. This arrangement, however, did not prove to be useful in recording changes taking place over the course of hours because an unchanging position of the hand cannot be maintained. Neither was measurement of maximal oesophageal pressure or maximal expiratory mouth pressure of value. These latter methods depend on the patient's degree of effort and are only pseudo-objective. The same objection holds for simple dynamometric testing. We are therefore left mainly with the patient's symptoms and the need for medication.

Anticholinesterase therapy could always be reduced during dialysis and had to be increased again after two to three weeks to the previous level. During this period, five patients felt better on a reduced medication level than they did on a higher dosage before dialysis.

Lacking truly objective measurement of improvement, we cannot disprove a purely psychological factor in the patients or in ourselves. We tried to avoid suggestive questioning, and, as the patients had been adjusting their own dosage, we told them to continue to do so. They were instructed to take medication to achieve a maximum state of improvement. We were impressed by the spontaneous and uniform retrospective statements of the patients even at the time of the relapse of symptoms. This uniformity in the response to dialysis and to the slow relapse afterwards is too striking to attribute to psychological influences which would be different from one patient to the next.

Keeping this issue of psychological influence constantly in mind, we do not consider it possible that the results can be entirely explained in this way. Furthermore, a point of interest in other respects as well, the absence of a close similarity between the effects of dialysis and those of anticholinesterase drugs is quite striking. Four patients reported improvement of symptoms such as ease in moving part of the face, or an increase in strength of the back and arms, which had been unsatisfactorily controlled under drug action. In other words, for some time after dialysis (even with reduced medication), some symptoms improved which were previously uncontrolled with high doses of drugs. We have not seen, however, a complete return to normality. Whether this is due to insufficient dialysis has not yet been determined.

A final argument against the explanation that this might be a purely psychological response is the fact that a prolonged dialysis is indeed an exhausting procedure with its attendant surgery, immobilization, and strain. We would expect the procedure to make symptoms worse, not better, unless some directly beneficial effect had occurred during dialysis.

A fourth point of view might be that the effect of dialysis was to alter the ionic balance, notably of those ions such as $\mathrm{K}^{+}, \mathrm{Mg}^{++}$, and $\mathrm{Ca}^{++}$, which have well-known effects on neuromuscular transmission and on muscle activity. 
Serum potassium was measured before dialysis on each of the 10 occasions. These ranged from 10.0 to $15.8 \mathrm{mg} . \%$ (average $14.0 \mathrm{mg} . \%$ ). After dialysis nine determinations (one technical error) were obtained varying between 14.1 and $26.3 \mathrm{mg}$. $\%$ (average $18.3 \mathrm{mg} . \%$ ). In the case of a transfer of potassium from the bath (135 litres) into the body, only minimal changes are to be expected in measurements of change in bath concentration as the volume of the two compartments are so widely different. Repeated measurements showed equal values.

We found no correlation between increase of serum potassium and benefit in dialysis. Whereas in one of the three patients whom we have classified as " unimproved" serum potassium rose from 13.5 to $26.3 \mathrm{mg}$. \%, Case 2 markedly improved, although serum potassium showed a decrease from 15.8 to $14.1 \mathrm{mg}$. \% Serum calcium before dialysis in all cases ranged from 8.2 to $10.4 \mathrm{mg} . \%$ (average $8.95 \mathrm{mg} . \%$ ). After dialysis the values ranged from 9.3 to $10.3 \mathrm{mg}$. $\%$ (average $9.71 \mathrm{mg}$. $\%$ ). Serum magnesium was not measured.

Although these measurements of possible ionic alterations are not complete, they do not, however, suggest any relation to improvement. Furthermore, improvement lasting two to three weeks would seem to be an unlikely consequence of a single alteration of an ionic balance.

It is our opinion that the beneficial effect is best explained by the hypothesis that the dialysis removes from the body a substance of low molecular weight which has a neuromuscular blocking action. Experimental work on it is now in progress and results will be published elsewhere. The authors feel that these results support strongly the experiments of Wilson and Stoner which also led to the same general conclusion.

Haemodialysis, clearly, will not become a routine treatment for myasthenia gravis. Further experience will be necessary to know whether it has a useful role in the management of myasthenic crises. We hope that these preliminary findings will encourage a fresh approach to the basic physiological mechanisms of this disease.

\section{Summary}

Five myasthenic patients were temporarily improved by haemodialysis. Improvement showed itself in partial amelioration of symptoms and signs and also by reduced need of medication. The benefit is tentatively explained by the removal of a circulating neuromuscular blocking substance.

We are greatly indebted to Dr. R. Wüthrich, of the Neurologische Poliklinik, Basel, and Dr. M. Mumenthaler, of the Neurologische Klinik, Zürich, for allowing us to treat their patients.

\section{REFERENCES}

Campbell, H., and Bramwell, E. (1900). Brain, 23, 277. Cited from Cohen, S. J. et al. (1945). Proc. Soc. exp. Biol. (N.Y.), 58, 181. Nastuk, W. L., Strauss, A. J. L., and Osserman, K. E. (1959). Amer, J. Med., 26, 394

Schwarz, H. (1952). Canad. med. Ass. J., 67, 238.

Struppler, A. (1955). Z ges. exp. Med., 125, 244. (1959). Med. Osaka Üniv., 10, 159.

Walker M. B (1934), Lancet, 1,1200

(1938). Proc. roy. Soc. Med., 31, 722.

Wilson, A., and Stoner, H. B. (1944). Quart. J. Med., 13, 1. 